I N S T I T U T O

DE

M E D I C I N A

T R O P I C A L

$\mathrm{DE}$

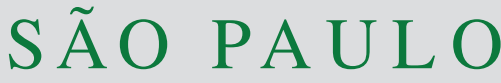

JOURNAL OF THE SÃO PAULO INSTITUTE OF TROPICAL MEDICINE

1Universidade Federal do Estado do Rio de Janeiro, Hospital Universitário Gaffrée e Guinle, Centro de Ciências Biológicas e da Saúde, Rio de Janeiro, Rio de Janeiro, Brazil

${ }^{2}$ Fundação Oswaldo Cruz, Laboratório de Biologia Molecular Aplicada a Micobactérias, Rio de Janeiro, Rio de Janeiro, Brazil

*Both authors contributed equally to the study

Correspondence to: Walter de Araujo Eyer-Silva Hospital Universitário Gaffrée e Guinle, Ambulatório de Alergia e Imunologia Clínica, Rua Mariz e Barros, 775, CEP 20270-004, Rio de Janeiro, RJ, Brazil

E-mail: walter.eyer@ig.com.br

Received: 8 October 2019

Accepted: 27 November 2019

\section{Antiretroviral therapy-induced paradoxical worsening of previously healed Mycobacterium haemophilum cutaneous lesions in advanced HIV infection}

\author{
Walter de Araujo Eyer-Silva ${ }^{\circledR 1 *}$, Marina Rodrigues de Almeida ${ }^{\circledR 1 *}$, Carlos \\ José Martins ${ }^{(1)}$, Rodrigo Panno Basílio-de-Oliveira ${ }^{\circledR 1}$, Luciana Ferreira de \\ Araujo ${ }^{1}$, Carlos Alberto Basílio-de-Oliveira1, Marcelo Costa Velho Mendes \\ de Azevedo ${ }^{10}$, Jorge Francisco da Cunha Pinto ${ }^{1}$ 1, Sidra Ezidio Gonçalves \\ Vasconcellos ${ }^{(i)}$, Ícaro Rodrigues-dos-Santos ${ }^{(1)}$, Harrison Magdinier \\ Gomes $^{\left({ }^{2} 2\right.}$, Philip Noel Suffys ${ }^{\circledR 2}$
}

\begin{abstract}
Mycobacterium haemophilum is a nontuberculous mycobacterium that causes localized or disseminated disease, mainly in immunocompromised hosts. We report the case of a 35-year-old HIV-infected woman who presented with several enlarging cutaneous lesions over the arms and legs. Histopathological examination revealed the diagnosis of a cutaneous mycobacterial disease. Mycobacterial analyses unveiled M. haemophilum infection. Six months after completion of a successful antimycobacterial treatment, she developed an immune reconstitution inflammatory syndrome (IRIS). This paradoxical relapse presented as tenderness, redness and swelling at the precise sites of the healed lesions and took place in the setting of significant recovery of the CD4 cell count (from 05 to 318 cells $/ \mathrm{mm}^{3}$ ). Microbiological analyses of these worsening lesions were negative, and they spontaneously remitted without the initiation of a novel antimycobacterial treatment cycle. M. haemophilum infection should always be considered as a cause of skin lesions in immunocompromised subjects. Physicians should be aware of the possibility of IRIS as a complication of successful antiretroviral therapy in HIV-infected patients with M. haemophilum infection.
\end{abstract}

KEYWORDS: AIDS. HIV infection. Immune Reconstitution Inflammatory Syndrome. Mycobacterium haemophilum. Nontuberculous mycobacterium.

\section{INTRODUCTION}

Mycobacterium haemophilum is a slow-growing nontuberculous mycobacterium that causes localized or disseminated disease, mainly in immunocompromised hosts ${ }^{1}$. It was first described and named in 1978 by Sompolinsky et al ${ }^{2}$ who recovered the organism from subcutaneous lesions of a woman with Hodgkin's disease. M. haemophilum exhibits unique requirements of iron supplementation to grow in vitro and shares close phylogenetic relatedness with $M$. leprae ${ }^{3}$. As it grows better at $30{ }^{\circ} \mathrm{C}$, disease is usually located in cooler places, mainly the lower and upper limbs of immunocompromised subjects. However, the organism may also cause a variety of other clinical presentations ${ }^{4}$. Due to its unique growth and temperature requirements, $M$. haemophilum infection may be underdiagnosed. We report a case of an antiretroviral therapy-induced immune reconstitution inflammatory syndrome (IRIS) on previously healed M. haemophilus cutaneous lesions in an 
HIV-infected patient whose antimycobacterial agents had been interrupted some months earlier.

\section{CASE REPORT}

A 35-year-old HIV-infected woman presented with a three-month history of enlarging cutaneous lesions over the arms and legs. The diagnosis of HIV infection was made 12 years earlier and she had a great difficulty adhering to the treatment. Previous complications of HIV infection included oropharyngeal candidiasis, Pneumocystis jirovecii pneumonia and Toxoplasma encephalitis. On clinical examination, there were around 20 brownish-red papules, plaques, nodules and ulcerative nodular lesions of variable sizes, some of which drained a seropurulent discharge, while others were covered with a hemorrhagic crust (Figure 1). The larger lesions were painful.

Laboratory evaluations were remarkable showing a normochromic, normocytic anemia with a hemoglobin of 9.1 $\mathrm{g} / \mathrm{dL}$ (reference values 13.8-17.2g/dL), CD4 cell count of 04 cells $/ \mathrm{mm}^{3}$ and plasma HIV viral load of 329,642 copies $/ \mathrm{mL}$ (5.5 $\mathrm{log} / \mathrm{mL})$. An HIV genotyping study showed no mutations associated with reduced drug susceptibility. Serological tests for hepatitis B, hepatitis C and syphilis were negative. There was no evidence of abdominal or thoracic disease. Microbiological analyses of an aspirate of seropurulent material, as well as a cutaneous biopsy, were performed as diagnostic procedures. Acid-fast staining of the seropurulent material showed mycobacterial structures. Histopathological examination of skin biopsy samples revealed diffuse inflammatory infiltrate in the reticular dermis, composed of histiocytes with abundant cytoplasm, as well as lymphocytes, plasma cells and neutrophils. An acid-fast staining of skin biopsies unveiled countless mycobacterial organisms, thus confirming the diagnosis of a cutaneous mycobacterial infection (Figure 2).

Therefore, seropurulent aspirate samples were used for species identification in a research laboratory specialized in mycobacteria. Due to unavailability of important laboratory supplies, these analyses took several months until a final result could be issued. While results were pending, antimycobacterial treatment was initiated with rifampin, ethambutol and clarithromycin. An antiretroviral combination consisting of tenofovir, lamivudine and raltegravir was also started. The skin lesions gradually improved over the ensuing weeks. One year later, the antimycobacterial combination was interrupted. The skin lesions had completely remitted, leaving hyperchromic scars (Figure 3A). However, the patient was on virological treatment failure: CD4 cell count was $05 / \mathrm{mm}^{3}$ and HIV plasma viral load was 141,227 copies/mL $(5.1 \mathrm{log} / \mathrm{mL})$. A novel HIV genotyping study showed the emergence of

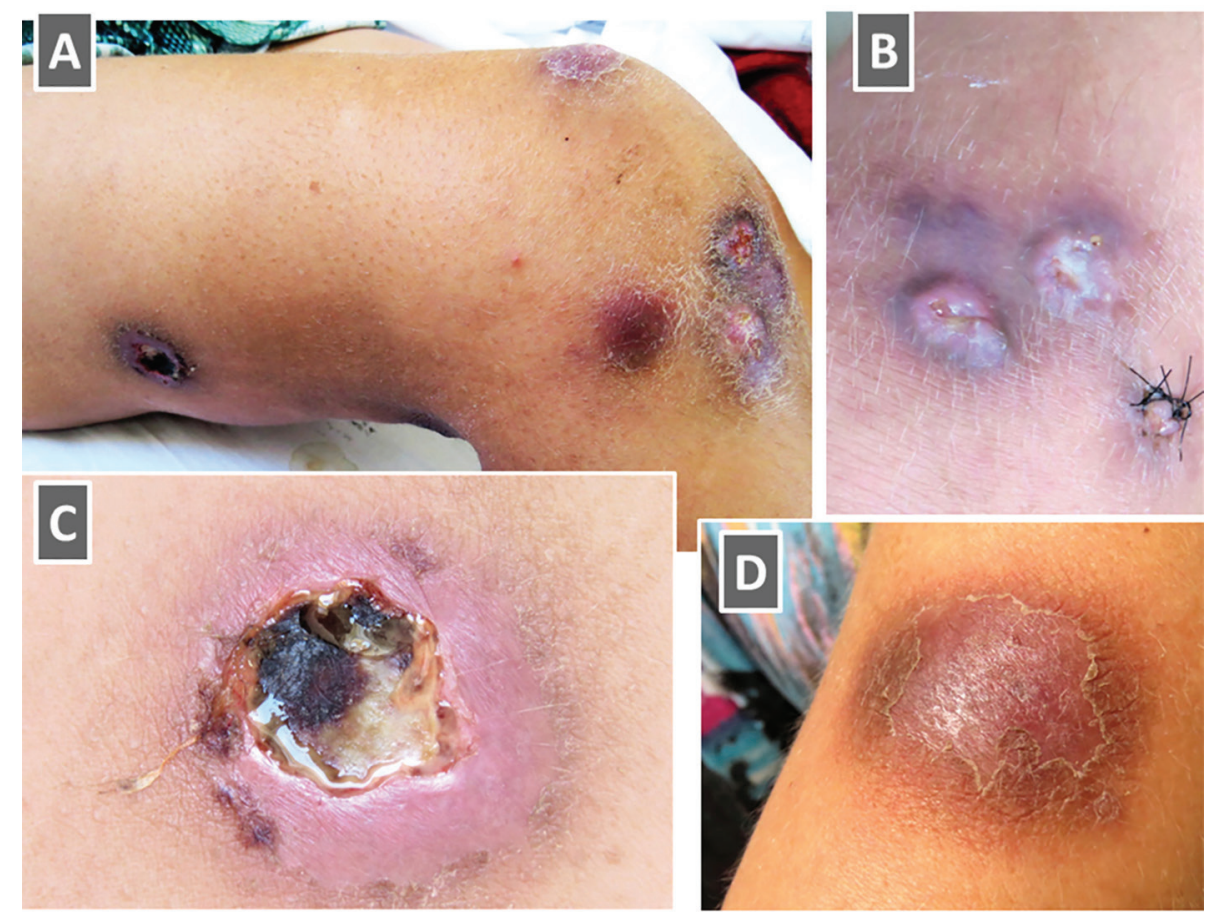

Figure 1 - Clinical images of a 35-year-old female patient who presented with a three-month history of growing cutaneous lesions on the arms and legs: A) brownish-red oval nodular papules and ulcerative nodular lesions of variable sizes on the right leg. Some lesions are confluent; B) Growing nodules covered by a purulent ulcer; C) A large ulcerative lesion draining a seropurulent discharge, with irregular undermined borders and surrounded by a thick rim of erythema. A central area of a hemorrhagic crust is seen; D) A large rounded plaque covered by a scaling surface, on the right arm. 


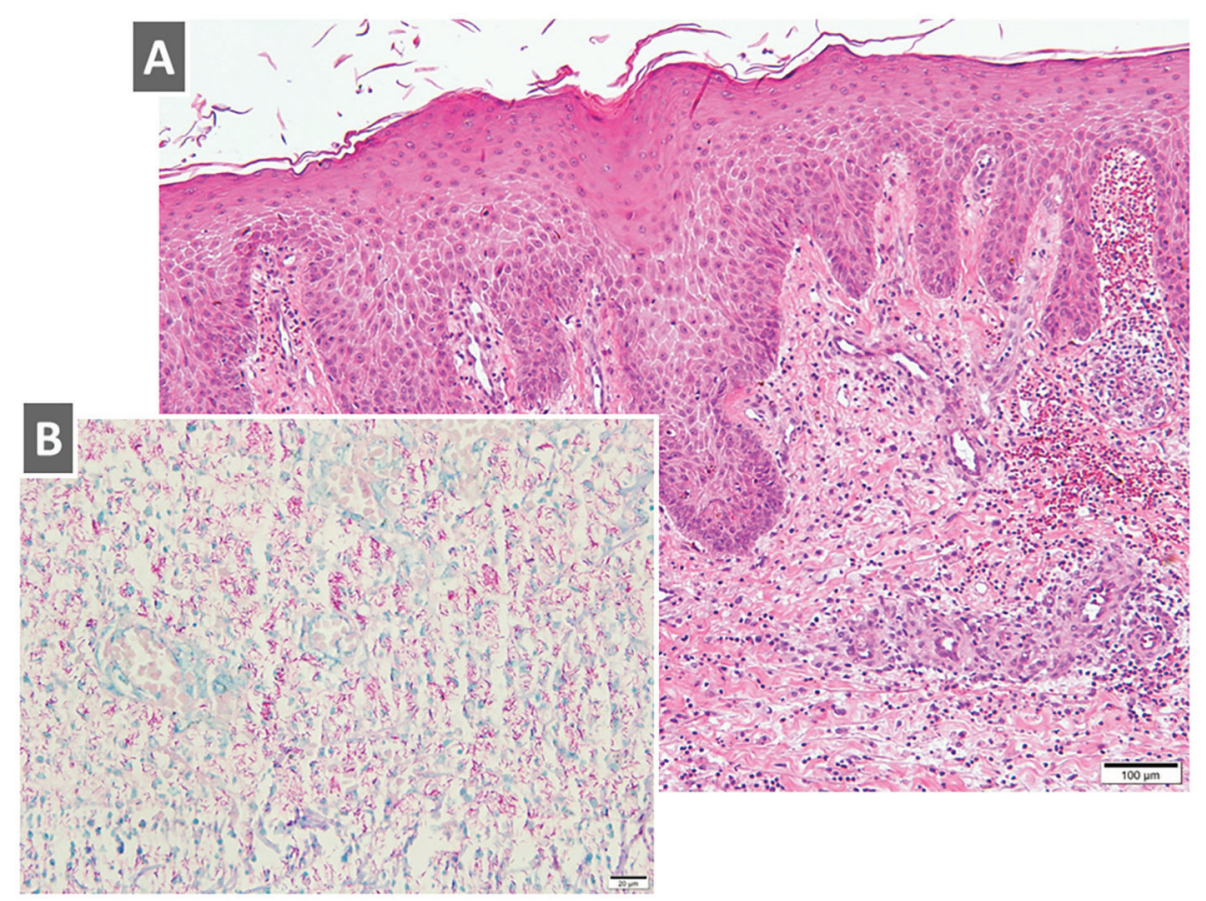

Figure 2 - Histopathological analyses of skin biopsy samples: A) Hematoxylin and eosin staining reveals diffuse inflammatory infiltrate in the reticular dermis, composed of histiocytes with abundant cytoplasm, as well as lymphocytes, plasma cells and neutrophils (original magnification $\mathrm{x} 40$ ); B) Acid-fast staining unveils countless mycobacterial organisms (original magnification $\mathrm{x} 400$ ).

mutations associated with reduced susceptibility to reverse transcriptase inhibitors (M184V) and integrase inhibitors (G140S, Q148R, G163R). Then, a new antiretroviral therapy combining tenofovir, lamivudine, ritonavir-boosted darunavir and etravirine was initiated. She was also kept on azithromycin and sulfamethoxazole-trimethoprim prophylaxis.

Six months after the antimycobacterial treatment interruption, the patient noted tenderness, redness and swelling at the precise sites of the previously healed
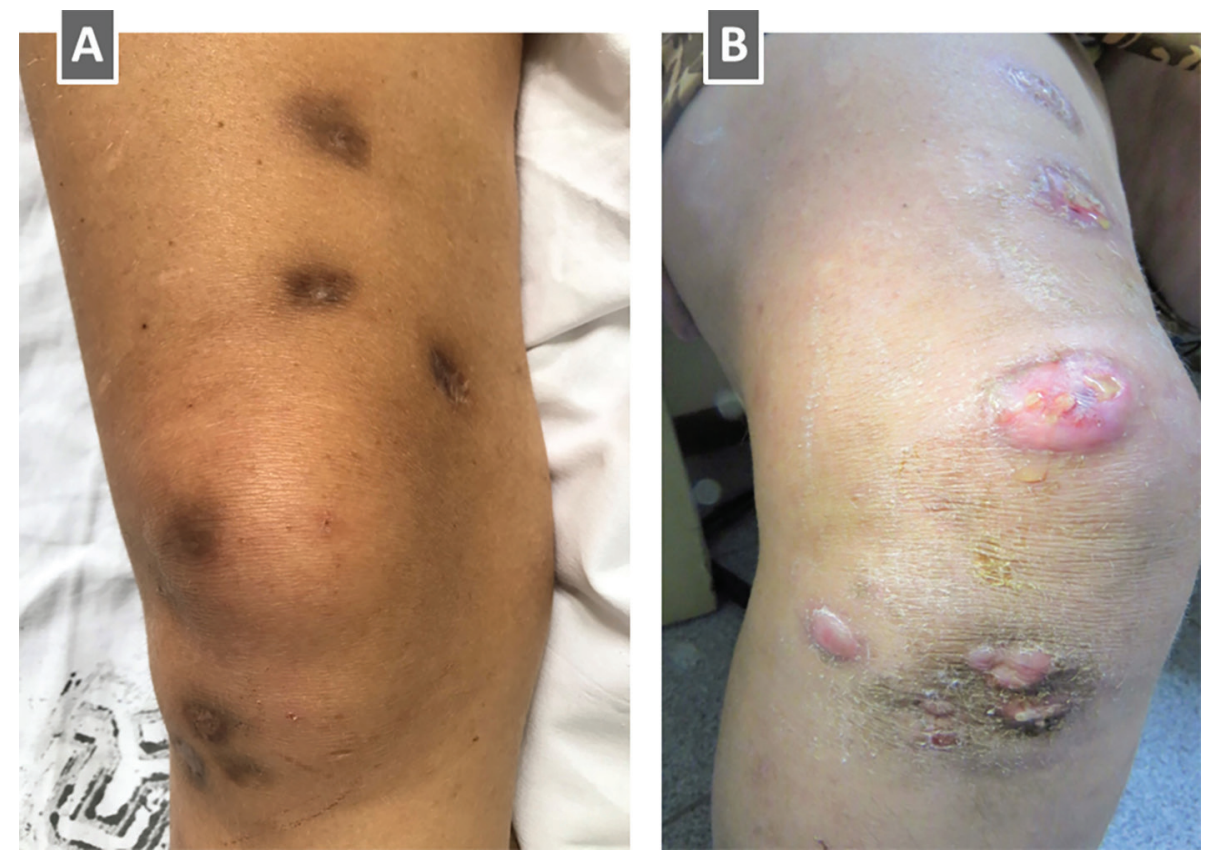

Figure 3 - A) Completely healed lesions with a hyperchromic scar; B) Immune reconstitution inflammatory syndrome six months after antimycobacterial treatment interruption. Redness and swelling at the precise locations of the previously healed lesions. Molecular and histopathological analyses failed to reveal mycobacteria. The lesions eventually improved spontaneously, while the patient was not on antimycobacterial treatment. 
M. haemophilus cutaneous lesions (Figure 3B). At this point, the CD4 cell count had significantly increased to $318 / \mathrm{mm}^{3}$ and the HIV plasma viral load had dropped to 331 copies $/ \mathrm{mL}(2.5 \log / \mathrm{mL})$. A novel cutaneous biopsy was performed and samples were sent again to the same laboratory specialized in mycobacteria. Histopathological analyses of the new biopsies revealed a necrotizing dermatitis with fibrinoid necrosis of the vessel walls and absence of mycobacterial structures. A novel cycle of antimycobacterial therapy was prescribed, but was only initiated five months later due to unavailability of rifabutin. During this five-month period, the lesions spontaneously and completely remitted, while the CD4 cell count kept increasing to $485 / \mathrm{mm}^{3}$ and the plasma HIV viral load fell to 116 copies $/ \mathrm{mL}(2.0 \mathrm{log} / \mathrm{mL})$. The paradoxical worsening of the previously healed lesions was consistent with IRIS. The patient has also developed herpes zoster in the right T6 dermatome. Even though, the lesions had spontaneously improved, an additional five months of rifabutin, ethambutol and clarithromycin was prescribed.

The results of mycobacterial species identification only became available by the end of this second round of antimycobacterial therapy. DNA extracted from the aspirate specimens was amplified by polymerase chain reaction (PCR) to detect bacterial DNA using primer sets targeting the $16 S$ rRNA, the $\beta$ subunit of bacterial RNA polymerase $(r p o B)$ and the $65 \mathrm{kDa}$ heat-shock protein (hsp65) gene (Supplementary Material). The $16 \mathrm{~S}$ rRNA, rpoB and hsp65 amplified DNA fragments with 99.89\%, $99 \%$ and $99 \%$ similarity with the corresponding regions of $M$. haemophilum, respectively. PCR results from the samples collected during the IRIS-related relapse were negative for the three target genes. Mycobacterial culture was not performed.

\section{DISCUSSION}

Cutaneous lesions in immunocompromised subjects are the most common presentation of $M$. haemophilum disease. These lesions usually present on the extremities, particularly the joints, and can be painful. The organism may also cause arthritis, osteomyelitis, dactylitis, tenosynovitis and lung disease ${ }^{5,6}$. Most reported cases occur in advanced HIV infection, but the disease also occurs in other immunosuppressed individuals, such as transplant recipients and patients who receiving immunosuppressants ${ }^{7-9}$. However, M. haemophilum may also cause cervical lymphadenitis in otherwise healthy children $^{10,11}$, and has been reported as a cause of chronic skin lesions after contact with marine corals ${ }^{12}$, of a pulmonary nodule in an immunocompetent host $^{13}$ and cutaneous lesions in freshly tattooed healthy adults ${ }^{14}$. There are currently no established guidelines on the ideal combination and duration of M. haemophilum treatment. Isolates are generally susceptible to clarithromycin, rifampin, rifabutin and ciprofloxacin ${ }^{15,16}$. However, all the isolates are resistant to ethambutol ${ }^{16}$. Our patient responded favorably to a combination of clarithromycin, rifabutin and ethambutol. The latter, was only prescribed because the species identification results were not yet available. Duration of therapy is in general guided by the underlying syndrome and the patient's immunological status ${ }^{17}$.Surgical excision may be considered for localized disease ${ }^{18}$.

IRIS is a well-known complication of tuberculous and nontuberculous mycobacterial infections. Most reported patients with nontuberculous mycobacterial IRIS had Mycobacterium avium complex infections. The three major clinical presentations are peripheral lymphadenitis, pulmonary-thoracic diseaseand intra-abdominal disease ${ }^{19}$. IRIS has already been described in the setting of M. haemophilum disease. Tyner et al. ${ }^{17}$ reported a case series of ten HIV-negative adult patients diagnosed between 2000 and 2015 with diseases caused by M. haemophilum. Seven of ten presented with skin lesions on the extremities and all but one had immunosuppressive conditions. Even though all the patients responded favorably to treatment, three developed worsening of previous lesions or emergence of new ones while on antimycobacterial treatment. Microbiological analyses of these worsened or new lesions were negative and all the patients eventually improved. Geisler et al. ${ }^{20}$ reported a similar case of an HIV-infected man with worsened $M$. haemophilum lesions while on antimycobacterial treatment. Two cases of M. haemophilum disease in HIV-infected subjects soon after initiation of antiretroviral therapy have also been described ${ }^{5,6}$. It remains to be determined whether M. haemophilum disease is more prone to the development of IRIS, when compared to disease caused by other mycobacterial species.

In summary, we present the case of an HIV-infected woman with advanced HIV-related immunosuppression in whom a paradoxical worsening of previously healed cutaneous $M$. haemophilum lesions occurred as a manifestation of IRIS. This relapse presented as tenderness, redness and swelling at the precise sites of the healed lesions and took place in the setting of significant recovery of CD4 cell count (from 05 to 318 cells $/ \mathrm{mm}^{3}$ ). Interestingly, the present report seems to be the only one in which paradoxical worsening and spontaneous remission of M. haemophilum cutaneous disease occurred while the patient was not on antimycobacterial treatment. Moreover, the patient has also developed herpes zoster, which is a well-recognized manifestation of IRIS. M. haemophilum 
infection should always be considered as a cause of skin lesions in immunocompromised subjects. Careful study of individual cases is of utmost importance to shed light on the full spectrum of its clinical presentations. M. haemophilum diagnosis and successful treatment require a concerted cooperation between clinicians, dermatologists, pathologists and mycobacteriologists.

\section{CONFLICT OF INTERESTS}

The authors declare no potential conflicts of interest with respect to the research, authorship, and/or publication of this article.

\section{INFORMED CONSENT}

A signed informed consent of the patient was obtained from the patient for publishing the case report and accompanying images.

\section{REFERENCES}

1. Lindeboom JA, Bruijnesteijn van Coppenraet LE, van Soolingen D, Prins JM, Kuijper EJ. Clinical manifestations, diagnosis, and treatment of Mycobacterium haemophilum infections. Clin Microbiol Rev. 2011;24:701-17.

2. Sompolinsky D, Lagziel A, Naveh D, Yankilevitz T. Mycobacterium haemophilum sp. nov., a new pathogen of humans. Int J Syst Bacteriol. 1978;28:67-75.

3. Tufariello JM, Kerantzas CA, Vilchèze C, Calder RB, Nordberg EK, Fischer JA, et al. The complete genome sequence of the emerging pathogen Mycobacterium haemophilum explains its unique culture requirements. MBio. 2015;6:e01313-15.

4. Franco-Paredes C, Marcos LA, Henao-Martínez AF, RodríguezMorales AJ, Villamil-Gómez WE, Gotuzzo E, et al. Cutaneous Mycobacterial infections. Clin Microbiol Rev. 2018;32:e006918.

5. Shah MK, Sebti A, Kiehn TE, Massarella SA, Sepkowitz KA. Mycobacterium haemophilum in immunocompromised patients. Clin Infect Dis. 2001;33:330-7.

6. Woodworth MH, Marquez C, Chambers H, Luetkemeyer A. Disabling dactylitis and tenosynovitis due to Mycobacterium haemophilum in a patient with human immunodeficiency virus/ acquired immune deficiency syndrome. Open Forum Infect Dis. 2017;4:ofx 165 .

7. Kamboj M, Louie E, Kiehn T, Papanicolaou G, Glickman M, Sepkowitz K. Mycobacterium haemophilum infection after alemtuzumab treatment. Emerg Infect Dis. 2008;14:1821-3.
8. Lau SK, Curreem SO, Ngan AH, Yeung CK, Yuen KY, Woo PC. First report of disseminated Mycobacterium skin infections in two liver transplant recipients and rapid diagnosis by hsp65 gene sequencing. J Clin Microbiol. 2011;49:3733-8.

9. Nishikawa R, Yamada Y, Kanki H, Matsuoka H, Nakamura T, Jikimoto T, et al. Case of Mycobacterium haemophilum misdiagnosed as Mycobacterium intracellulare due to one base insertion in the bacterial genome. J Dermatol. 2018;45:64-6.

10. Dawson DJ, Blacklock ZM, Kane DW. Mycobacterium haemophilum causing lymphadenitis in an otherwise healthy child. Med J Aust. 1981;2:289-90.

11. Lindeboom JA, Prins JM, Bruijnesteijn van Coppenraet ES, Lindeboom R, Kuijper EJ. Cervicofacial lymphadenitis in children caused by Mycobacterium haemophilum. Clin Infect Dis. 2005;41:1569-75.

12. Smith S, Taylor GD, Fanning EA. Chronic cutaneous Mycobacterium haemophilum infection acquired from coral injury. Clin Infect Dis. 2003;37:e100-1.

13. White DA, Kiehn TE, Bondoc AY, Massarella SA. Pulmonary nodule due to Mycobacterium haemophilum in an immunocompetent host. Am J Respir Crit Care Med. 1999;160:1366-8.

14. Kay MK, Perti TR, Duchin JS. Tattoo-associated Mycobacterium haemophilum skin infection in immunocompetent adult, 2009. Emerg Infect Dis. 2011;17:1734-6.

15. Atkinson BA, Bocanegra R, Graybill JR. Treatment of Mycobacterium haemophilum infection in a murine model with clarithromycin, rifabutin, and ciprofloxacin. Antimicrob Agents Chemother. 1995;39:2316-9.

16. Griffith DE, Aksamit T, Brown-Elliott BA, Catanzaro A, Daley C, Gordin F, et al. An official ATS/IDSA statement: diagnosis, treatment, and prevention of nontuberculous mycobacterial diseases. Am J Respir Crit Care Med. 2007;175:367-416.

17. Tyner HL, Wilson JW. Fifteen-year clinical experience with Mycobacterium haemophilum at the Mayo Clinic: a case series. J Clin Tuberc Other Mycobact Dis. 2017;8:26-32.

18. McGovern J, Bix BC, Webster G. Mycobacterium haemophilum skin disease successfully treated with excision. J Am Acad Dermatol. 1994;30:269-70.

19. Phillips P, Bonner S, Gataric N, Bai T, Wilcox P, Hogg R, et al. Nontuberculous mycobacterial immune reconstitution syndrome in HIV-infected patients: spectrum of disease and long-term follow-up. Clin Infect Dis. 2005;41:1483-97.

20. Geisler WM, Harrington RD, Wallis CK, Harnisch JP, Liles WC. Broad spectrum of dermatologic manifestations caused by Mycobacterium haemophilum infection. Arch Dermatol. 2002;138:229-30. 


\section{SUPPLEMENTARY MATERIAL}

The following molecular biology methods were used. Bacterial DNA was extracted from skin biopsy and aspirate specimens by using the DNeasy Blood \& Tissue kit (Qiagen Biotecnologia) following the manufacturer's guidelines. Amplifications were performed using primer sets targeting the $16 S$ rRNA (16S P1-F/ 5-TGCTTAACACATGCAAGTCG-3 and $16 S$ P2new/ 5- TCTCTAGACGCGTCCTGTGC-3), the $\beta$ subunit of bacterial RNA polymerase $(r p o B \mathrm{~F} /$ 5-GGCAAGTC ACCCCGAAGGG-3 and rpoBR/ 5-AGCGGCTGCTGGGTGATCATC-3), and the $65 \mathrm{kDaheat}-$ shock protein $h s p 65 \mathrm{~F} / 5$-ATCGCCAAGGAGATCGAGCT3) and $h s p 65 \mathrm{R} / 5$-AAGGTGCCGCGGATCTTGTT-3). PCR master mix contained 5X KAPA2G Robust HotStart ReadyMix, $10 \mu \mathrm{M}$ each of the primers, $5 \%$ DMSO (100\%), PCR-grade water and $5 \mu \mathrm{L}$ of target DNA for the $25 \mu \mathrm{L}$ of final of reaction volume. Amplifications were performed in a Veriti Thermal Cycler (Applied Biosystems, Thermo Fisher Scientific, Waltham, Massachusetts, USA), performed using the following cycling conditions. For $16 \mathrm{~S}$ rRNA: an initial denaturation step of $3 \mathrm{~min}$ at $95^{\circ} \mathrm{C}$, followed by 40 cycles of $15 \mathrm{~s}$ at $94^{\circ} \mathrm{C}, 15 \mathrm{~s}$ at $60^{\circ} \mathrm{C}$, and $15 \mathrm{~s}$ at $72{ }^{\circ} \mathrm{C}$, and ending with a final elongation step for $1 \mathrm{~min}$ and $30 \mathrm{~s}$ at $72{ }^{\circ} \mathrm{C}$; rpoB: an initial denaturation step of $3 \mathrm{~min}$ at $95^{\circ} \mathrm{C}$, followed by 35 cycles of $15 \mathrm{~s}$ at $94{ }^{\circ} \mathrm{C}, 15 \mathrm{~s}$ at $60{ }^{\circ} \mathrm{C}$, and $15 \mathrm{~s}$ at $72{ }^{\circ} \mathrm{C}$, and ending with a final elongation step for $1 \mathrm{~min}$ at $7{ }^{\circ} \mathrm{C}$; and $h$ sp 65: an initial denaturation step of $3 \mathrm{~min}$ at $95^{\circ} \mathrm{C}$, followed by 35 cycles of $15 \mathrm{~s}$ at $94{ }^{\circ} \mathrm{C}, 15 \mathrm{~s}$ at $64^{\circ} \mathrm{C}$, and $30 \mathrm{~s}$ at $72{ }^{\circ} \mathrm{C}$, and ending with a final elongation step for $1 \mathrm{~min}$ and $30 \mathrm{~s}$ at $72{ }^{\circ} \mathrm{C}$. PCR assays included samples containing DNA of M. tuberculosis strain H37Rv (ATCC 27294T) and M. leprae NHDP-55 when appropriate, as positives controls. All the controls consistently provided the expected results for each of the screened genes. Negative control PCRs containing no template DNA, were also included to control DNA contamination. The amplicon sequencing was performed using the BigDye Terminator kit (PE Applied Biosystems) on an ABI 3730 DNA Analyzer, at the Oswaldo Cruz Foundation (PDTIS DNA Sequencing Platform/FIOCRUZ, Rio de Janeiro, Brazil). The analysis of gene sequences was performed using SeqScape ${ }^{\circledR}$ and Chromas $^{\circledR}$ softwares, the sequences were aligned and compared with database using Blast (https://blast.ncbi.nlm. nih.gov/Blast.cgi). 